\title{
Cross-Country Perspective on Reverse Pathway Dynamics Between Teachers' Self-Efficacy and Job Satisfaction
}

\author{
loannis Katsantonis ${ }^{1 \star}$
}

${ }^{1}$ Department of Primary Education, University of Patras, GREECE
*Corresponding Author: ioanniskatsantonis@upnet.gr

Citation: Katsantonis, I. (2021). Cross-Country Perspective on Reverse Pathway Dynamics Between Teachers' Self-Efficacy and Job Satisfaction. Pedagogical Research, 6(2), em0092. https://doi.org/10.29333/pr/9726

\begin{abstract}
ARTICLE INFO
Received: 9 Jul. 2020

Accepted: 4 Oct. 2020

ABSTRACT

The purpose of this study was to examine the reverse pathway dynamics between teachers' self-efficacy and job satisfaction from a cross-country perspective. By recognizing the sparseness of empirical studies on the reciprocal relation between self-referent assessment of capabilities and job satisfaction, a model of reciprocal determinism between teacher self-efficacy and job satisfaction is proposed. The data of 51,782 primary school teachers were analyzed using a non-recursive causal reciprocal structural equation system within the overarching framework of structural equation modeling. The results indicated that teachers' self-efficacy was reciprocally related to job satisfaction at the individuals' level. Despite this finding, feedback effects were identified only across seven education systems. Further, it was shown via multigroup structural equation modeling that organizational culture (i.e., education systems) by proxy of the countries was moderating the structural relations among the recursive and non-recursive effects of the model. These findings underscore the importance of self-efficacy in promoting job satisfaction and indicate that more satisfied teachers are characterized also by greater teaching self-efficacy. The results are discussed within the scope of better understanding the relations between these two focal constructs for educational practice.
\end{abstract}

Keywords: teachers' self-efficacy, job satisfaction, cross-national research, non-recursive structural equation modeling, feedback loops, reciprocal causation

\section{INTRODUCTION}

Teacher self-efficacy and job satisfaction have become a focal point of researchers' interest in the field of psychology of education by being closely connected with teachers' well-being and psychological resilience (Katsantonis, 2020a; Skaalvik \& Skaalvik, 2014). Many studies to date have found evidence in favor of the unidirectional relation of self-efficacy and job satisfaction, both at the teachers' level (e.g., Caprara et al., 2003; Høigaard et al., 2012; Tschannen-Moran \& Hoy, 2007) and at the principals' level (e.g., Federici, 2013; Federici \& Skaalvik, 2012).

Both teacher self-efficacy and job satisfaction have been connected with many teacher- and student-related outcomes, such as teacher- student relations (Admiraal et al., 2019), teacher burnout (Høigaard et al., 2012), teacher motivation (Canrinus et al., 2012), school climate factors (Katsantonis, 2020a; Zakariya, 2020), etc. Despite the abundant evidence of the various interactions between teacher self-efficacy and job satisfaction, the majority, if not all, the theoretical and empirical studies have dealt with unidirectional regressive effects. Specifically, teacher self-efficacy is specified to exert either a direct or a mediating effect on job satisfaction (e.g., Canrinus et al., 2012; Caprara et al., 2003; Malinen \& Savolainen, 2016; Zakariya, 2020), but the potential feedback effect is not estimated.

Thus, this study, by utilizing psychological lens, seeks to thoroughly investigate the extent to which the reciprocal effects between teacher self-efficacy and job satisfaction within the context of the Heuristic Model of Teacher Self-Efficacy (Zee \& Koomen, 2016) could be empirically supported. The examination of the reciprocal relationship between teacher self-efficacy and variables that constitute aspects of teachers' psychological well-being could be of great instructional value and would extend the theoretical underpinnings of the relationship between these two important psychological variables.

\section{Theoretical Framework}

\section{(Teacher) Self-efficacy}

Self-efficacy has been primarily studied within the theoretical framework of the Locus of Control and the Social Cognitive theory (Labone, 2004; Zee \& Koomen, 2016). In the present article, self-efficacy will be discussed from the perspective of the Social 


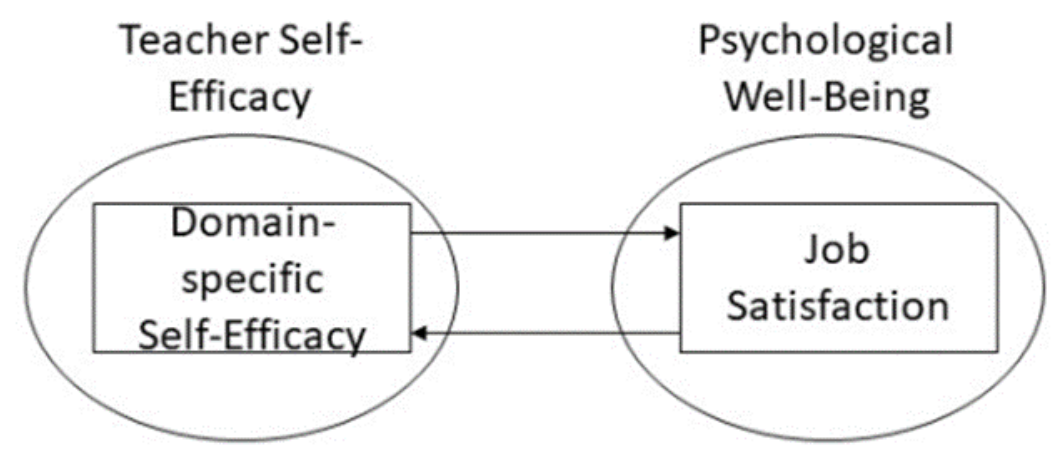

Figure 1. Part of the Heuristic Model of Teacher Self-Efficacy

Cognitive Theory. From this perspective, self-efficacy concerns a self-evaluation of an individual's capability that stimulates cognitive, affective, and motivational processing which determines the transformation of knowledge and capabilities into agency (Bandura, 1997). However, self-efficacy should not be considered disjointly from context (Labone, 2004). Teachers' perspective is this study's focus. Therefore, the locus is transferred from general self-efficacy to teacher self-efficacy. According to TschannenMoran et al. (1998) the second construct refers to "teacher's belief in his or her capability to organize and execute courses of action required to accomplish a specific teaching task in a particular context" (p. 233). Self-efficacy is a "manifold" construct in such a way that it exerts influence not only on agency and by extension on behavior, but also on cognition and affect (Zee \& Koomen, 2016). Beyond the above, an important component of Social Cognitive theory is the concept of "reciprocal determinism" (Bandura, $1978,1997)$. It is theorized that cognitive, affective and environmental factors are in a state of constant, reciprocal interaction. The self, the society, and the personal attributes are connected bidirectionally, but not necessarily with equal strength (Bandura, 1997).

The reciprocal determinism hypothesis has been examined within various contexts, either from the student or the teacher perspective. For example, from the student point of view, researchers have investigated the reciprocal effects between students' mathematics performance and self-efficacy (Williams \& Williams, 2010). From the teacher perspective, for instance, self-efficacy was found to be reciprocally related to teachers' job engagement and work resources (Simbula et al., 2011). Despite the fact that self-efficacy and job satisfaction can both be considered personal attributes, a relatively new sociocognitive model of teacher selfefficacy, called the Heuristic Model of Teacher Self-Efficacy (Zee \& Koomen, 2016), has proposed the potential existence of a feedback relation between these two variables. However, the studies regarding the reciprocal association between teacher selfefficacy and job satisfaction are sparse.

\section{On the association of teacher self-efficacy and job satisfaction}

As a foreword, it should be mentioned that job satisfaction has elicited the interest of research in the field of organizational psychology (see Katsantonis, 2020a). Job satisfaction refers to personal accomplishment, pleasure, and satisfaction that are derived from occupation (Collie et al., 2012). Studies have examined recursive (i.e., unidirectional) relations among the various dimensions of teacher self-efficacy and job satisfaction. Most of the empirical studies concern the mediating effects of teacher self-efficacy. For instance, many studies have found that teacher self-efficacy mediates the association between school climate and job satisfaction (cf., Aldridge \& Fraser, 2015; Malinen \& Savolainen, 2016; Skaalvik \& Skaalvik, 2014). Other studies have found that self-efficacy directly influences job satisfaction (cf., Klassen \& Chiu, 2010; Vieluf et al., 2013; Wang et al., 2015). Researchers have also connected teachers' self-efficacy will lower levels of work stress and/ or coping with stress (cf., Betoret, 2006, Katsantonis, 2020b; Schwarzer \& Hallum, 2008). These aforementioned studies are but a glimpse of the wider literature that regards the positive association between teachers' self-efficacy and the various dimensions of job satisfaction.

\section{The heuristic model of teacher self-efficacy}

From the Social Cognitive theoretical perspective, the subjects during the process of composition of self-referent assessment draw upon the degree of satisfaction with the task at hand as a reflection of their level of capability to execute the process at hand (Bandura, 1997). As Zee and Koomen (2016) mention, to the intricate nature of teacher self-efficacy adds the reciprocity that underlies the relation between teacher self-efficacy and third constructs. Drawing upon the Social Cognitive theory and the accumulated research on teachers' self-efficacy and its consequences, and antecedents, Zee and Koomen (2016) have proposed the Heuristic Model of Teacher Self-Efficacy. Teacher self-efficacy, quality of classroom processes (i.e., didactic and affective support; organization), students' academic adjustment (performance and motivation), as well as teachers' psychological wellbeing (i.e., job satisfaction; coping; stress; engagement; burnout, etc.) are the main components of this model. These components are all linked bidirectionally. For instance, Brouwers et al. (2001) used a sample of 277 secondary-school teachers in the Netherlands and by utilizing non-recursive SEM showed that teacher self-efficacy is a focal construct in a cyclical feedback loop among eliciting support from the school environment, burnout dimensions, and job performance. Despite this, in the current study, only the bidirectional association of teacher self-efficacy and job satisfaction (i.e., a part of psychological well-being) will be considered. Conceptually, the part of the model that will be tested is shown in Figure 1.

In sum, Zee and Koomen (2016) call for empirical studies that will thoroughly examine the hypothesized reciprocity between teacher self-efficacy and job satisfaction, closing, thus, a long-standing gap in the international literature. Following the above 
recommendation, Granziera and Perera (2019) have examined the reciprocal hypothesis between self-efficacy and job satisfaction. These investigators drew a sample of 595 Australian primary and secondary school teachers and utilized cross-lagged panel models to examine reciprocal effects between teacher self-efficacy and job satisfaction. These authors' results indicated an indirect, but not a direct, reciprocal effect between teacher self-efficacy and job satisfaction through work engagement. As can be seen, there is much to be learned yet by examining the reciprocal relationship between teacher self-efficacy and job satisfaction. For instance, the research could focus on why there is an indirect feedback and not a direct one.

\section{The Present Study}

Previous studies (Tschannen-Moran et al., 1998; Tschannen-Moran \& Hoy, 2007) have stressed the lack of literature that supports the reciprocal determinism hypothesis between teacher self-efficacy beliefs and school contexts. Specifically, a major gap in the literature was identified regarding the reciprocity between teacher self-efficacy and job satisfaction (Zee \& Koomen, 2016). Although studies have examined unidirectional and mediating effects between self-efficacy and job satisfaction and third variables (e.g., Malinen \& Savolainen, 2016; Schwarzer \& Hallum, 2008; Wang et al., 2015), the feedback relationship between selfefficacy and job satisfaction is not examined in these studies.

Towards closing this apparent gap, Granziera and Perera (2019) have made the first step to longitudinally model the "reciprocal causation" between self-efficacy and job satisfaction. However, their study has only provided evidence of indirect reciprocity, instead of a direct reciprocal effect, which is also suggested by the Heuristic Model of Teacher Self-Efficacy (Zee \& Koomen, 2016). Although Bandura's theory (1978), that is the basis for the Heuristic Model (Zee \& Koomen, 2016), presents arguments in favor of direct and indirect reciprocal causation, instead of a partial bidirectional reciprocal effect, the most crosssectional datasets do not allow for an examination of indirect feedback effects because of the technical difficulties that such models present (Kline, 2013). Therefore, to test the reciprocal links between self-efficacy and job satisfaction, as elaborated on in the Heuristic model of teacher self-efficacy, we hypothesize that a direct feedback effect should exist between teacher self-efficacy and job satisfaction.

Further, as self-efficacy and job satisfaction have been shown to be differentiated as a function of organizational culture (i.e., educational systems- see Vieluf et al., 2013), we may reasonably assume that feedback effects are not invariant across all educational systems. Thus, a cross-national (i.e., across educational systems) by proxy of the countries testing of feedback effects between teacher self-efficacy and job satisfaction is much needed to determine whether different educational systems (i.e., organizational cultures) moderate the magnitude of the reciprocal relations. Thus, the stability of the bidirectionality, as proposed by the Heuristic Model (Zee \& Koomen, 2016), will be confirmed or rejected. Therefore, the subsequent research questions and hypotheses were formulated based on the presented theoretical framework.

RQ1: Does a feedback effect exist between teacher self-efficacy and job satisfaction at the individuals' level?

RQ2: Is a feedback effect apparent across all educational systems?

RQ3: Is the feedback effect between these two focal variables differentiated as a function of educational systems (i.e., by proxy of the country)?

In this study, we hypothesize that a direct feedback effect will be apparent at the individuals' level across all educational systems (Hypothesis 1). Further, it is expected that the reciprocal determinism hypothesis would be supported across all educational systems (Hypothesis 2). Finally, it is assumed that educational systems will moderate the structural reciprocal relations between self-efficacy and job satisfaction (Hypothesis 3).

\section{METHOD}

\section{Participants}

This study draws upon the data of the Teaching and Learning International Survey by OECD (2019). The data were collected in late 2017/ early 2018 and are publicly available from June 2019 and onwards. The survey was cross-sectional in nature. OECD (2019) assured that the research procedures and protocols were subjected to ethics approval in all participating countries and economies. In the present study, only the responses of $N=51,782$ of primary school teachers from 15 countries were considered.

Overall, the present data were derived from the following countries: Australia, Flemish Community- Belgium, Buenos Aires/Argentina, Denmark, England, France, Japan, Korea, Netherlands, Spain, Sweden, Taiwan/ Chinese Taipei, Turkey, United Arab Emirates, and Viet Nam. In-detail distribution of the sample can be found in OECD (2019). These countries were selected because they represent diverse educational systems and are either among the high or low scoring in international student assessment surveys ${ }^{1}$. Therefore, the examination of the proposed model can provide more information on the processes that drive teachers' effectiveness and psychological well-being.

\section{Measures}

The instruments, that were used in the present study, were validated by OECD (2019). Measurement invariance of all the instruments has been thoroughly examined and the associated evidence is provided in the TALIS 2018 technical report. The interested readership is referred to OECD (2019) for an in-depth discussion about the scales' reliability coefficients and measurement invariance level across countries. It should be mentioned, though, that all scales, that were used in the present

\footnotetext{
${ }^{1}$ See https://www.oecd.org/pisa/
} 
Table 1. Item wordings for the teacher self-efficacy scale

\begin{tabular}{cl}
\hline Self-efficacy in classroom management \\
\hline 1. & Control disruptive behavior in the classroom. \\
\hline 2. & Make my expectations about student behavior clear. \\
\hline 3. $\quad$ Get students to follow classroom rules. \\
\hline Self-efficacy in instruction \\
\hline 1. $\quad$ Craft good questions for students \\
\hline 2. $\quad$ Use a variety of assessment strategies \\
\hline 3. & Provide an alternative explanation, for example when students are confused \\
\hline S. & Vary instructional strategies in my classroom \\
\hline Self-efficacy in student engagement \\
\hline 2. $\quad$ Get students to believe they can do well in school work \\
\hline 3. & Motivate students who show low interest in school work \\
\hline 4. & Help students think critically \\
\hline Note: Item wordings were retrieved from OECD (2019)
\end{tabular}

Table 2. Item wordings for the job satisfaction scales

\begin{tabular}{|c|c|}
\hline Job sati & action with work environment \\
\hline 1. & I would like to change to another school if that were possible. \\
\hline 2. & I enjoy working at this school. \\
\hline 3. & I would recommend this school as a good place to work. \\
\hline 4. & All in all, I am satisfied with my job. \\
\hline Job sati & action with profession \\
\hline 1. & The advantages of being a teacher clearly outweigh the disadvantages. \\
\hline 2. & If I could decide again, I would still choose to work as a teacher. \\
\hline 3. & I regret that I decided to become a teacher. \\
\hline 4. & I wonder whether it would have been better to choose another profession. \\
\hline
\end{tabular}

study, were at least invariant at the metric level. This level of invariance is sufficient enough to permit comparisons of regressive effects and correlations (see Katsantonis, 2020b).

\section{Teachers' self-efficacy}

The teachers' self-efficacy scale comprised 12 items of the widely used TSES short-form scale by Tschannen-Moran and Woolfolk Hoy (2001), with a different scoring system (OECD, 2019), though. The scale prompt asked the participants "In your teaching, to what extent can you do the following?". The items were scored using a four-point Likert-type scale ranging from 1 "Not at all" to 4 "A lot". An overall composite score (coded as T3SELF) was formed by OECD (2019) using the subscales of "Selfefficacy in classroom management" (T3SECLS), "Self-efficacy in instruction" (T3SEINS), and "Self-efficacy in student engagement" (T3SEENG). Stratified Cronbach's coefficient alpha ranged from .882 to .945 across countries. For McDonald's coefficient omega, the readers are referred to OECD (2019). Item wordings for this scale can be found in Table 1.

\section{Teachers' job satisfaction}

The teacher job satisfaction scale comprised 8 items that described teachers' perceptions about the job and particularly about their satisfaction with the work environment and the profession. The items were scored using a four-point Likert-type scale ranging from 1 "Strongly Disagree" to 4 "Strongly Agree". An overall composite score (coded as T3JOBSA) was formed by OECD (2019) using the subscales of "Job satisfaction with work environment" (T3JSENV) and "Job satisfaction with profession" (T3JSPRO). Stratified Cronbach's coefficient alpha ranged from .855 to .948 across countries. For McDonald's coefficient omega, the readers are referred to OECD (2019). Item wordings for this scale may be found in Table 2.

\section{Statistical Procedures}

Pre-processing of the data was carried out through SPSS 23 (IBM Corp. 2015). The estimation of the parameters of the nonrecursive model was conducted via the Lavaan 0.6-6 package (Rosseel, 2012) in the statistical language and environment $R$ (R Core Team, 2018). Although reciprocal relations are typically investigated in the SEM framework with cross-lagged panel models, we may use a non- recursive model as a proxy to the equivalent longitudinal model (Wong \& Law, 1999). Due to the non-recursive nature of the estimated model, a full-information estimator is deemed necessary (Maartens \& Haase, 2006; Schaubroeck, 1988, 1990). Thus, the maximum likelihood estimator (MLR) with the Yuan- Bentler T2* scaled test statistic (Yuan \& Bentler, 2000) and robust against non-normality Huber- White standard errors were employed to estimate the parameters. Missing data were handled with the full-information maximum likelihood method (FIML-Enders \& Bandalos, 2001). Drawing upon econometrics (Wooldridge, 2013), we apply the instrumental variable approach within the SEM framework to estimate reciprocal relations (Breznau, 2018) between the two variables of interest, i.e., teacher self-efficacy and job satisfaction.

It should be noted that particular attention would be paid to the issue of endogeneity. Endogeneity refers to the biased effects in a regression equation that arise in the case of reciprocity between two variables. To tackle this challenge, instrumental variables 


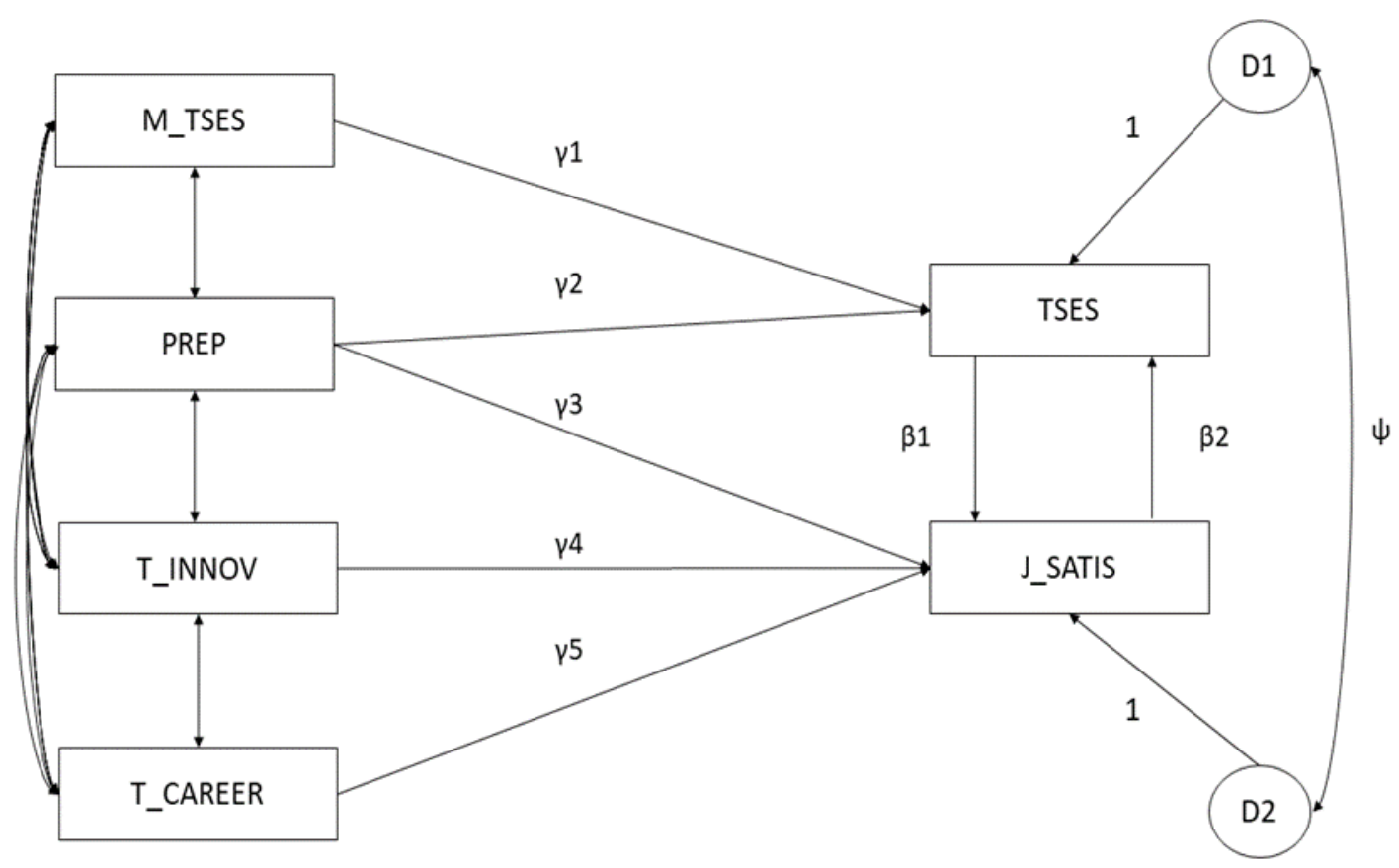

Figure 2. Non- recursive causal reciprocal structural equation model with a direct feedback loop between teacher self-efficacy (TSES) and job satisfaction (J_SATIS)

must be incorporated into the model to preclude biased results and incorrect conclusions (Wooldridge, 2013). Another important consideration for this type of analysis is model identification (Berry, 1984; Heise, 1975). According to Kline (2016), two assumptions must be met to achieve identification of each of the reciprocally related parameters, i.e., the order and the rank conditions. Whether these two conditions have been satisfied, can be determined by using matrix algebra (see Paxton, Hipp, \& Marquart-Pyatt, 2011). However, by identifying relevant and substantial instruments, one can conclude that both the order and the rank conditions have been fully satisfied (Maartens \& Haase, 2006). To achieve identification of the model as a whole, auxiliary instrumental variables (AIVs) were selected for the purposes of the present study (Bollen, 2012).

Additional assumptions must be considered before testing a non-recursive SEM model. Firstly, the chosen instruments must have a substantial effect on the respective endogenous variable. The instruments should also not be affecting the other endogenous variable inside the non-recursive subset of the model. These assumptions may be supported by a non-significant chisquare goodness-of-fit test (Bollen, 2012; Breznau, 2018). The above is also indicative of the instruments' quality. Moreover, the estimation of a covariance $(\psi)$ between the endogenous variables of the non- recursive subset is necessary to fortify the reciprocal effects from confounding or the omission of control variables (Wong \& Law, 1999).

Finally, in the present study, CFI and TLI values above 0.95 and RMSEA and SRMR values less than 0.06 are deemed acceptable and the models are partially retained or rejected on the basis of these fit indices (see Hu \& Bentler, 1999); however, in this study, we also place greater emphasis on the chi-square goodness-of-fit test due to the non-recursive nature of the models. Latent variables were not included in the current parameterization to achieve a more parsimonious solution and to facilitate structural invariance analyses. The composite variables, that were used in the present study, are latent trait scores nearly absolved from measurement error and appropriately weighted by the importance of the selected responses. The TALIS 2018 (OECD, 2019) technical report describes extensively how these latent trait scores were derived from confirmatory factor analyses. The nonrecursive structural equation model was specified as shown in Figure 2.

\section{Instrumental Variables Identification}

For the present study, we initially proposed "self-related efficacy in multi-cultural classrooms" (M_TSES) and "preparedness in instruction" (PREP) as instrumental variables for teachers' self-efficacy (TSES). Multi-cultural self-efficacy refers to self-efficacy beliefs in carrying out instructional and behavioral tasks in a culturally diverse classroom environment. Multi-cultural self-efficacy is assumed to be closely related to teachers' self-efficacy if we consider that both theoretical constructs reflect teachers' awareness of their effectiveness in executing instruction-related tasks. Additionally, the culturally diverse context of a classroom is known to affect the personal self-efficacy beliefs of teachers (Knoblauch \& Woolfolk Hoy, 2008). The multi-cultural self-efficacy composite variable was computed from a 5-items scale. Stratified Cronbach' coefficient alpha ranged from 0.711 to 0.913 across all countries. Item wordings for this scale can be found in Table 3.

Teachers' preparedness is conceptualized as the teachers' feelings of the (in-) adequacy of their formal education or training in preparing them for various facets of teaching. Teachers' preparedness has been shown to affect aspects of teachers' self-efficacy (Darling-Hammond et al., 2002; Giallo \& Little, 2003; Rots \& Aelterman, 2009). The teachers' preparedness composite variable was computed from a 12-items scale. Although the initial scale included 12 items, participants from Denmark did not respond to all 12 items and, thus, Denmark was excluded from the analyses. Stratified Cronbach' coefficient alpha ranged from 0.802 to 0.956 across 
Table 3. Item wordings of the multi-cultural self-efficacy scale

\begin{tabular}{cl}
\hline 1. & Cope with the challenges of a multicultural classroom \\
\hline 2. & Adapt my teaching to the cultural diversity of students \\
\hline 3. & Ensure that students with and without a migrant background work together \\
\hline 4. & Raise awareness for cultural differences amongst students \\
\hline 5. & Reduce ethnic stereotyping amongst students
\end{tabular}

Note: Item wordings were retrieved from OECD (2019)

Table 4. Item wordings for the teacher preparedness scale

\begin{tabular}{ll}
\hline 1. & Content of some or all subject(s) I teach. \\
\hline 2. & Pedagogy of some or all subject(s) I teach. \\
\hline 3. & General pedagogy. \\
\hline 4. & Classroom practice in some or all subject(s) I teach. \\
\hline 5. & Teaching in a mixed ability setting. \\
\hline 6. & Teaching in a multicultural or multilingual setting. \\
\hline 7. & Teaching cross-curricular skills (e.g. creativity, critical thinking, problem solving). \\
\hline 8. & Use of ICT (information and communication technology) for teaching \\
\hline 9. & Student behaviour and classroom management. \\
\hline 10. & Monitoring students' development and learning. \\
\hline 11. & Facilitating students' transitions from <ISCED 2011 level $0>$ to <ISCED 2011 level 1>. \\
\hline 12. & Facilitating play.
\end{tabular}

Note: Item wordings were retrieved from the TALIS questionnaire

Table 5. Item wordings for the team innovativeness scale

\begin{tabular}{cl}
\hline 1. & Most teachers in this school strive to develop new ideas for teaching and learning. \\
\hline 2. & Most teachers in this school are open to change. \\
\hline 3. & Most teachers in this school search for new ways to solve problems. \\
\hline 4. & Most teachers in this school provide practical support to each other for the application of new ideas.
\end{tabular}
Note: Item wordings were retrieved from OECD (2019)

all countries. In this study, we expect a positive effect of preparedness (PREP) and multi-cultural self-efficacy (M_TSES) on teachers' self-efficacy. Item wordings for the teacher preparedness scale may be found in Table 4.

Regarding the job satisfaction (J_SATIS) variable, we identified variables that mostly pertain to the school context. For instance, whether teaching was the participants' first career option (T_CAREER) was incorporated into the model as an instrument for job satisfaction. Teaching as a first career choice is a subcomponent of teachers' background factors, and teachers' characteristics have long been thought of as antecedents of teacher job satisfaction (Bolin, 2007). It is assumed that participant teachers who elected to teach as their first choice of profession, would be more satisfied with their job. Although teacher preparedness has been initially proposed as an instrument for teacher self-efficacy, Green and Muñoz (2016) have shown also that preparedness was a very strong predictor of teachers' job satisfaction $(\beta=0.59)$. Therefore, we permitted a second regression path from teacher preparedness to job satisfaction. This choice does not allow us to assume that teacher preparedness is an instrument for self-efficacy. Despite this, only one unique instrument is needed for each of the reciprocally related variables (Gennetian et al., 2008). Both of the regression paths were retained (for similar examples see Paxton et al., 2011).

A second instrument for teacher job satisfaction was team innovativeness, that is, teachers' perceptions of the degree of general innovativeness of all teachers in the target school (OECD, 2019). This composite variable was computed from a 4-items scale. Stratified Cronbach' coefficient alpha ranged from 0.840 to 0.953 across all countries. Team innovativeness is thought of as a part of the "job resources" that shrink potentially negative effects on teachers' psychological well-being (Katsantonis, 2020b), and enhance teachers' work engagement (Ainley \& Carstens, 2019). As job satisfaction is an important component of teachers' well-being and resilience (Katsantonis, 2020a), we may reasonably assume that team innovativeness would positively influence teachers' job satisfaction. Item wordings for the team innovativeness scale can be found in Table $\mathbf{5}$.

\section{RESULTS}

\section{Testing the Feedback Loop Between Teacher Self-Efficacy and Job Satisfaction}

Prior to commencing the main analyses, multilevel variance components models (i.e., no predictor models) were conducted to examine the extent to which there is clustering bias with respect to countries and schools. Based on the variance components models, the intraclass correlation coefficient (ICC) for teacher self-efficacy with respect to the country cluster was negligible, $\rho=0.020$. For job satisfaction, the ICC was equal to $\rho=0.012$. Regarding the schools as the clustering variable, the ICC for the teacher self-efficacy was also neglectable with $\rho=0.020$. Similar results were found for job satisfaction, $\rho=0.012$. Therefore, we conclude that there are effectively no clustering effects because the ICCS were below the 0.05 cutoff value and we may proceed with the analyses as usual (Heck \& Thomas, 2020).

At the individual level, the full sample of $N=49,190$ participants was utilized to test the hypothesized model (see Figure 1). It should be noted that Denmark was excluded from all analyses because Danish participants did not respond to all the preparedness 
Table 6. Unstandardized parameter estimates of the feedback effects between teacher self-efficacy and job satisfaction across countries

\begin{tabular}{|c|c|c|c|c|c|c|c|c|}
\hline Country & $\gamma 1$ & $\gamma 2$ & $\mathrm{\gamma 3}$ & ү4 & $\gamma 5$ & $\beta 1$ & $\beta 2$ & $\psi$ \\
\hline \multirow{2}{*}{ Argentina } & $0.256^{\star \star \star}$ & $0.043^{\star \star \star}$ & -0.005 & $0.123^{\star \star \star}$ & $0.331^{\star \star \star}$ & $0.369^{\star \star \star}$ & $0.420^{\star \star \star}$ & $-1.481^{\star \star \star}$ \\
\hline & $(0.289)$ & $(0.192)$ & $(-0.024)$ & $(0.170)$ & $(0.094)$ & $(0.383)$ & $(0.405)$ & $(-0.574)$ \\
\hline \multirow{2}{*}{ Belgium } & $0.249^{\star \star \star}$ & $0.021^{\star \star \star}$ & $0.031^{\star \star \star}$ & $0.270^{\star \star \star}$ & $0.458^{\star \star \star}$ & $0.239^{*}$ & $0.247^{\star \star \star}$ & $-1.326^{\star \star \star}$ \\
\hline & $(0.267)$ & $(0.069)$ & $(0.083)$ & $(0.232)$ & $(0.090)$ & $(0.196)$ & $(0.301)$ & $(-0.417)$ \\
\hline \multirow{2}{*}{ Netherlands } & $0.158^{\star \star \star}$ & 0.003 & $0.038^{\star \star \star}$ & $0.240^{\star \star \star}$ & $0.327^{\star \star \star}$ & $0.381^{*}$ & $0.355^{\star \star \star}$ & $-1.750^{\star \star \star}$ \\
\hline & $(0.234)$ & $(0.010)$ & $(0.107)$ & $(0.197)$ & $(0.082)$ & $(0.299)$ & $(0.452)$ & $(-0.629)$ \\
\hline \multirow{2}{*}{ Spain } & $0.384^{\star \star \star}$ & $0.038^{\star \star \star}$ & -0.004 & $0.188^{\star \star \star}$ & $0.450^{\star \star \star}$ & $0.373^{\star \star \star}$ & $0.223^{\star \star \star}$ & $-1.213^{\star \star \star}$ \\
\hline & $(0.326)$ & $(0.139)$ & $(-0.016)$ & $(0.236)$ & $(0.101)$ & $(0.409)$ & $(0.204)$ & $(-0.405)$ \\
\hline \multirow{2}{*}{ Sweden } & $0.303^{\star \star \star}$ & $0.061^{\star \star \star}$ & -0.014 & $0.212^{\star \star \star}$ & $0.466^{\star \star \star}$ & $0.492^{\star \star \star}$ & $0.190^{\star}$ & $-1.773^{\star \star \star}$ \\
\hline & $(0.279)$ & $(0.222)$ & $(-0.047)$ & $(0.186)$ & $(0.103)$ & $(0.457)$ & $(0.205)$ & $(-0.488)$ \\
\hline \multirow{2}{*}{ Korea } & $0.272^{\star \star \star}$ & $0.081^{\star \star \star}$ & -0.013 & $0.168^{\star \star \star}$ & -0.119 & $0.342^{\star \star \star}$ & $0.550^{\star \star \star}$ & $-4.033^{\star \star \star}$ \\
\hline & $(0.268)$ & $(0.280)$ & $(-0.047)$ & $(0.154)$ & $(-0.015)$ & $(0.359)$ & $(0.524)$ & $(-0.710)$ \\
\hline \multirow{2}{*}{ Vietnam } & $0.169^{\star \star \star}$ & $0.061^{\star \star \star}$ & $0.034^{\star \star \star}$ & $0.128^{\star \star \star}$ & $0.821^{\star \star \star}$ & $0.188^{\star}$ & $0.443^{\star \star \star}$ & $-1.118^{\star \star \star}$ \\
\hline & $(0.245)$ & $(0.152)$ & $(0.095)$ & $(0.190)$ & $(0.134)$ & $(0.209)$ & $(0.399)$ & $(-0.514)$ \\
\hline
\end{tabular}

Note: "'significant at $\mathrm{p}<0.001$; "significant at $\mathrm{p}<0.01$; "significant at $\mathrm{p}<0.05$; Standardized parameters are inside the parentheses; Statistical significance was determined based on the unstandardized solution

items. The model's fit to the sample covariance matrix was excellent, i.e., $\chi^{2}(1)=0.381, p>0.05, \mathrm{CFI}=1.00, \mathrm{TLI}=1.00, \mathrm{RMSEA}=0.000$ $90 \% \mathrm{Cl}[0.000 ; 0.000], \mathrm{SRMR}=0.000$. The effect of self-efficacy on job satisfaction was positive, i.e., $b=0.352, p<0.001, \beta=0.346$. The feedback effect was also positive, i.e., $b=0.338, p<0.001, \beta=0.344$. Both clusters of instrumental variables were statistically significant. Multi-cultural self-efficacy was positively affecting teacher self-efficacy, $b=0.278, \beta=0.278, p<0.001$. Regarding the second cluster of instruments for job satisfaction, both team innovativeness and teaching as a first career choice were substantial instruments, $\mathrm{b}=0.174, p<0.001, \beta=0.180 ; \mathrm{b}=0.622, p<0.001, \beta=0.116$, respectively. Preparedness as a common predictor was exerting a positive effect with respect to teacher self-efficacy, $b=0.046, p<0.001, \beta=0.188$, but a negative effect with respect to job satisfaction, $b=-0.008, p<0.001, \beta=-0.032$. To examine whether the reciprocally related parameters were of equal strength we compared two nested models, namely one model with equality constraints on the feedback loop and the freely estimated model. The Satorra- Bentler delta chi-square test indicated that the reciprocal effects were of equal magnitude, $\Delta \chi^{2}(1)=0.338, p>0.05$.

As a preliminary step before cross-country analyses, single-group SEM were examined separately for each country, following Sass and Schmitt's (2013) recommendation. Among the 14 countries included in the dataset, only 7 countries were included in the subsequent analyses, namely Argentina, Belgium, Spain, Korea, Netherlands, Sweden, and Vietnam. The rationale for the selection of these countries was based on the validity of the instrumental variables and the existence of reciprocal effects, as determined by single-group analyses. That is, the aforementioned instruments were "well behaving" and reciprocal effects were apparent in the selected educational systems. In the United Arab Emirates dataset, the instruments were not functioning as expected, i.e., $\chi^{2}$ $(1)=52.287, p<0.05, \mathrm{CFI}=0.986, \mathrm{TLI}=0.795, \mathrm{RMSEA}=0.07590 \% \mathrm{Cl}[0.058 ; 0.093]$, SRMR 0.012 . In Turkey, the instruments were also not "well-behaving", i.e., $\chi^{2}(1)=6.350, p<0.05, \mathrm{CFI}=0.996, \mathrm{TLI}=0.947, \mathrm{RMSEA}=0.04190 \% \mathrm{CI}[0.000 ; 0.000]$, SRMR=0.007. Invalid instruments were also found in Taiwan, i.e., $\chi^{2}(1)=12.565, p<0.05, \mathrm{CFI}=0.992, \mathrm{TLI}=0.878, \mathrm{RMSEA}=0.05790 \% \mathrm{Cl}[0.000 ; 0.000]$, $\mathrm{SRMR}=0.010$. Although in the English dataset, the instruments were well-behaving, i.e., $\chi^{2}(1)=1.384, p>0.05, \mathrm{CFI}=0.999, \mathrm{TLI}=$ 0.987 , RMSEA $=0.01490 \% \mathrm{Cl}[0.000 ; 0.000]$, SRMR $=0.005$, reciprocal effects were not found. Despite the valid instruments in France, i.e., $\chi^{2}(1)=0.422, p>0.05, \mathrm{CFI}=1.00, \mathrm{TLI}=1.028$, RMSEA $=0.00090 \% \mathrm{Cl}[0.000 ; 0.000]$, SRMR $=0.003$, reciprocal effects were not found. Same results were found for the Australian dataset, i.e., $\chi^{2}(1)=1.942, p>0.05, \mathrm{CFI}=0.999, \mathrm{TLI}=0.981, \mathrm{RMSEA}=0.01890 \% \mathrm{Cl}[0.000$; 0.000 ], $\mathrm{SRMR}=0.004$. Similar were the results in the Japanese dataset, i.e., $\chi^{2}(1)=2.912, p>0.05, \mathrm{CFI}=0.998, \mathrm{TLI}=0.977$, RMSEA= $0.02590 \% \mathrm{Cl}[0.000 ; 0.060]$, SRMR $=0.005$.

Next from a cross-country perspective, the model was specified as a multigroup following the Jöreskog (1971) tradition. The multiple-group structural model displayed excellent fit to the sample covariance matrix, i.e., $\chi^{2}(7)=7.898, p>0.05, \mathrm{CFI}=1.00, \mathrm{TLI}=$ $0.998, \mathrm{RMSEA}=0.00690 \% \mathrm{Cl}[0.000 ; 0.023]$, SRMR $=0.002$. The exact fit hypothesis was also supported, which means that the selected instruments for this sample have no influence beyond that which was pre-specified (Breznau, 2018). That does not mean, though, that other alternative models with equal good fit do not exist. Overall, seven countries, namely Argentina, Belgium, Spain, Korea, Netherlands, Sweden, and Vietnam, displayed statistically significant feedback effects. In Table 6, the unstandardized and standardized $(\beta s)$ structural coefficients for each group per pathway, along with the covariance $(\psi)$ are presented. Finally, the correlation root mean squared residuals (CRMR) along with their associated $p$-values were computed for each group to identify possible misfit. Across all groups herein, the CRMR values ranged from 0.000 to 0.007 and all were not statistically significant (i.e., $p>0.05)$. For a detailed description of the pathways' labels, please refer to Figure 2.

\section{Examining the Moderating Effect of Educational Systems}

To examine the moderating effect of organizational culture on the feedback loop, structural invariance was examined. A case of non-invariance is indicative of the moderating effect of the grouping variable (Holmbeck, 1997; Sass \& Schmitt, 2013)- in this case, the educational system by proxy of the countries.

In the first step, we imposed equality constraints on the recursive effects (Model A). Model A was then compared to the Baseline model which was the proposed multigroup SEM (see also Figure 2). Model A displayed a modest fit according to the approximate goodness-of-fit indices, i.e., $\chi^{2}(37)=415.023, p<0.001, \mathrm{CFI}=0.950, \mathrm{TLI}=0.858$, RMSEA $=0.05590 \% \mathrm{Cl}[0.051 ; 0.060]$, SRMR=0.026. However, the Satorra- Bentler delta chi-square test indicated that the Model A as compared to the Baseline Unconstrained model 
Table 7. Structural Invariance- $\triangle$ approximate Goodness-of-Fit Indices for Progressively More Constrained Models

\begin{tabular}{|c|c|c|c|c|c|c|}
\hline Model & $x^{2}(d f)$ & $\mathrm{CFI}$ & $|\Delta \mathrm{CFI}|$ & RMSEA & $|\triangle \mathrm{RMSEA}|$ & $\Delta \mathrm{x}^{2}(\mathrm{df})$ \\
\hline $\begin{array}{l}\text { Unconstrained } \\
\text { Baseline }\end{array}$ & $\begin{array}{c}7.898 \\
(7)\end{array}$ & 1.00 & & 0.006 & & \\
\hline Model A & $\begin{array}{c}415.023^{* * \star} \\
(37)\end{array}$ & 0.950 & & 0.055 & & $\begin{array}{c}390.46^{* * *} \\
(30)\end{array}$ \\
\hline Model B & $\begin{array}{c}23.772 \\
(17)\end{array}$ & 0.999 & $0.001 \dagger$ & 0.012 & $0.006 \dagger$ & $\begin{array}{c}15.678 \dagger \\
(10)\end{array}$ \\
\hline Model C & $\begin{array}{c}54.415^{* * *} \\
(29)\end{array}$ & 0.996 & $0.004 \uparrow \dagger$ & 0.017 & $0.011 \dagger \dagger$ & $\begin{array}{l}46.048^{* *} \\
(22) \dagger \dagger\end{array}$ \\
\hline Model D & $\begin{array}{c}25.156 \\
(24)\end{array}$ & 1.00 & $0.000 \dagger t \dagger$ & 0.006 & $0.000 \dagger \dagger \dagger$ & $\begin{array}{c}17.302 \dagger \dagger \dagger \\
(17)\end{array}$ \\
\hline
\end{tabular}

Note: $\uparrow ; \uparrow ; \uparrow \uparrow \uparrow$ Compared with the baseline model

was degraded, i.e., Satorra- Bentler $\Delta x^{2}(30)=390.46, p<0.001$. To identify which recursive effects were non-invariant, a series of Lagrange Multiplier (LM) tests (Bollen, 1989) were conducted. Each updated model was compared to the previous one until no statistically significant difference was found. The final updated model with the relaxed constraints (Model B) was compared to the Baseline Unconstrained model and was invariant, i.e., Satorra- Bentler $\Delta \mathrm{X}^{2}(10)=15.678, p>0.05$.

In the next step of the analyses, equality constraints were imposed on the non-recursive paths of Model $B$. The new constrained Model $C$ was degraded as compared to the Baseline model, i.e., Satorra- Bentler $\Delta X^{2}(22)=46.048, p<0.001$. The LM test indicated that there were indeed non-invariant non-recursive paths. Univariate LM tests were run to determine in which groups the nonrecursive paths were unequal. The final updated model with the relaxed constraints (Model D) was compared to the Baseline Unconstrained model. The Satorra- Bentler delta chi-square difference test indicated that Model D was statistically identical from a model-data fit perspective, i.e., $\Delta X^{2}(17)=17.302, p>0.05$. In Table 7, the goodness-of-fit indices for the above models are presented for comparative reasons.

\section{DISCUSSION}

To sum up, the purpose of the present study was threefold: Firstly, an examination of potential feedback effects between teacher self-efficacy and job satisfaction at the individual level was conducted. Secondly, we investigated whether the reciprocity hypothesis between these two variables generalized to all the educational systems under study. Finally, the moderating effect of the different educational systems was considered. All these were addressed in the current study in order to understand whether this part (see Figure 1) of the Heuristic Model of Teacher Self-Efficacy (Zee \& Koomen, 2016) is stable across all educational systems. In short, the results of this study are in favor of a direct feedback effect between teacher job satisfaction and self-efficacy. Specifically, it should be mentioned that the present study is the first one, to the best of our knowledge, to examine these partially bidirectional feedback relations between self-efficacy and job satisfaction across educational systems. Thus, initial evidence could be found in this study in support of the reciprocal relations between self-efficacy and psychological well-being, as described by the Heuristic Model of Teacher Self-Efficacy (Zee \& Koomen, 2016).

Contrary to the findings of Granziera and Perera (2019), our results indicated the existence of a direct feedback effect between self-efficacy and job satisfaction. Specifically, a positive effect from self-efficacy to job satisfaction results in a positive effect from job satisfaction to self-efficacy. In other words, these two psychological variables are involved in a mutually enhancing dependence, where increases in one variable result certainly in inflated levels in the other, at least in seven educational systems.

It should be noted that at the individual unit of analysis, the specified reciprocal relations were found to be statistically significantly positive in both directions and the instruments were functioning exactly as expected. That is, the model implied individual-level pooled-within countries covariance matrix was exceptionally well-fitting to the corresponding data covariance matrix. Thus, hypothesis 1 was confirmed. On the other hand, despite the existence of the reciprocal effects, as evidenced by the structural coefficients of the individual level model, the statistical significance of these relations did not transcend all educational systems. In other words, the direct feedback effect was not invariant. Excluding one educational system (i.e., Denmark) that did not meet the study's inclusion criteria, among the other 14 educational systems only 7 were characterized by "well-behaving" instruments and a statistically significant reciprocal effect (see Table 6). Thus, hypothesis 2 is partially confirmed. Despite the fact that in 4 other educational systems (i.e., England, Australia, France, Japan), the instrumental variables were "well-behaving", feedback effects were not found. This finding underscores the fact that longitudinal research is most probably needed to confirm this result.

If we consider the five clusters of similar educational systems that were proposed by Bulle's (2011) taxonomy of the participating countries in the PISA program, we could descriptively compare the countries regarding the existence of the psychological feedback effect between job satisfaction and self-efficacy. That is, we observe that in the East-Asian educational system, which is comprises Japan and Korea, the reciprocity hypothesis is supported in Korea but not in Japan (see Results section). Heterogeneity with respect to the feedback effects was also evident in the Latin model of educational systems (i.e., France, Greece, Italy, Spain). Specifically, we found that teacher self-efficacy was reciprocally related to job satisfaction in Spain, but not in France. On the other hand, in the Germanic cluster (i.e., Austria, Belgium, Netherlands, Switzerland), we found that the assumption of homogeneity of the existence of the reciprocal effects was tenable because feedback effects were evident in both Belgium and the Netherlands. In the Anglo-Saxon cluster (i.e., England; Australia), no reciprocal feedback effects were identified, 
which is in compliance with the findings of Granziera and Perera (2019). Only one country, namely Sweden, was representing the Northern model (i.e., Denmark, Finland, Iceland, Norway, Sweden) in our study, and, therefore, a comparison and possible generalizations are not possible. Regrettably, the excluded four educational systems could have provided rich information for within-cluster descriptive comparisons, however, due to the outlined technical reasons, it was unfeasible to appropriately estimate the non-recursive model.

Regarding the last research question, at the individual unit of analysis, the comparison of the two nested models, namely the one with equality constraints on the feedback loop and the freely estimated model, showed that the feedback relation is balanced with respect to the magnitude of the effects. Despite this, the picture we get from the cross-country examination of these effects is entirely different.

When equality constraints were imposed on both the recursive and the non-recursive structural coefficients of the proposed model, the more restricted models were rejected. These results confirmed hypothesis 3 . That is, the delta chi-square tests of between-model differences were statistically significant in both cases compared to the unconstrained models (see Models A and $C$ in Table 7). Specifically, the greatest attrition was observed across educational systems in the paths from preparedness (PREP) to teacher self-efficacy (TSES) and job satisfaction (T_SATIS). That is, we could hypothesize that in each country's programs of initial teacher training/ education different weight is given to different components of teacher training/ education and this differentiation has a moderating effect on the relation between preparedness and self-efficacy. This may have also been the cause for the negative coefficient of regression path from teacher preparedness to job satisfaction, that was observed in some countries. Other possible interpretations could be considered in a future study.

The other notable feature of the analysis of Model $C$ is not the fact that the reciprocal effects between the two variables are not of equal magnitude, but the fact that the moderating effect of organizational culture by proxy of the country was less severe than in the recursive subset of the model. This finding is indicative of the necessity to understand better the nature of the unequal positive feedback effects between self-efficacy and job satisfaction across the samples studied here. However, it is to be noted that the unequal magnitude of these feedback effects concedes with the Social Cognitive view of the reciprocal determinism hypothesis (Bandura, 1997), which is the basis for the Heuristic Model of Teacher Self-Efficacy (Zee \& Koomen, 2016), that states clearly that the reciprocal effects could be of unequal magnitude and could be differentiated as a function of differences in circumstances and individuals (Bandura, 1978). This also strengthens our argument that calls for further and more extensive crosscountry level-oriented comparisons of the reciprocity hypothesis.

\section{CONCLUSION AND IMPLICATIONS FOR FURTHER RESEARCH}

The results of the current study showed that more self-efficacious teachers are also characterized by greater psychological well-being in terms of being more satisfied with their work. The inverse is also true; that is, in the selected seven educational systems, teachers who are more satisfied with their work are also characterized by greater self-efficacy. This finding is, at least from our point of view, of great importance for policy-making because it shows that in order to raise teachers' personal teaching self-efficacy, job satisfaction should be considered firstly. If we place this finding within the job-resources model (Xanthopoulou et al., 2007), then we can conclude that more personal resources which are involved in a dynamic relation, such as job satisfaction and self-efficacy, may be needed in order to enhance these professionals' levels of psychological well-being in the workplace. Furthermore, further studies are needed in order to examine potential ecological/ eco-systemic factors that may play the role of moderator of the reciprocal relationship between psychological well-being and domain-specific self-efficacy.

Despite the above, more longitudinal research is needed to determine which variable is "driving" this reciprocal relation. Further, by utilizing cross-lagged panel models, future research may focus on the potential growth that is observed between selfefficacy and job satisfaction. In other words, researchers may concentrate their efforts to examine how this regressive relation develops over time.

\section{Limitations}

Although the present study is among the first, to our knowledge, that sought to confirm the direct feedback loop between teacher self-efficacy and job satisfaction, it does not mean that these relations are generalizable to the whole population of teachers in the respective countries. Additionally, due to technical issues, we were unable to concurrently consider "reciprocal causation" in the other 4 countries (i.e., United Arab Emirates, Turkey, Taiwan/ Chinese Taipei, Denmark). Moreover, it should be noted that the four educational systems, that were excluded from the analyses, should be considered in a future study in order to identify "well-behaving" instrumental variables that could potentially unveil reciprocal relationships. Finally, these findings could be thought of as the stepping stone upon which researchers in organizational psychology may base their future investigations on how this reciprocity may be apparent in other occupations. Further, in this study, we did not position this non-recursive model within a broader framework of job-resources and job-demands, which could have proven highly informative with respect to teachers' working conditions and psychological well-being in the workplace. Thus, there is much to be learned yet by more research in this field.

Funding: No funding source is reported for this study.

Declaration of interest: No conflict of interest is declared by author. 


\section{REFERENCES}

Admiraal, W., Veldman, I., Mainhard, T., \& van Tartwijk, J. (2019). A typology of veteran teachers' job satisfaction: Their relationships with their students and the nature of their work. Social Psychology of Education, 22, $337-355$. https://doi.org/10.1007/s11218-018-09477-z

Ainley, J., \& Carstens, R. (2019). Teaching and learning international survey (TALIS) 2018 conceptual framework. Paris, France: OECD Publishing. https://doi.org/10.1787/799337c2-en

Aldridge, M. J., \& Fraser, J. B. (2015). Teachers' views of their school climate and its relationship with teacher self-efficacy and job satisfaction. Learning Environment Research, 19, 291-307. https://doi.org/10.1007/s10984-015-9198-x

Bandura, A. (1978). The self-system in reciprocal determinism. American Psychologist, 33(4), 344-358. https://doi.org/10.1037/0003-066X.33.4.344

Bandura, A. (1997). Self-efficacy: The exercise of control. New York, NY, USA: W.H. Freeman and Company.

Berry, D. W. (1984). Nonrecursive causal models. Newbury Park, London, UK: Sage Publications.

Betoret, D. F. (2006). Stressors, self-efficacy, coping resources, and burnout among secondary school teachers in spain. Educational Psychology, 26(4), 519-539. https://doi.org/10.1080/01443410500342492

Bolin, F. (2007). A study of teacher job satisfaction and factors that influence it. Chinese Education and Society, 40(5), 47-64. https://doi.org/10.2753/CED 1061-1932400506

Bollen, K. (1989). Structural equations with latent variables. New York, NY, USA: Wiley Publications

Bollen, K. (2012). Instrumental variables in sociology and the social sciences. Annual Review of Sociology, 38, 37-72. https://doi.org/10.1146/annurev-soc-081309-150141

Breznau, N. (2018). Simultaneous feedback models with macro-comparative cross-sectional data. methods, data, analyses, 12(2), 265-308. https://doi.org/10.12758/mda.2017.07

Brouwers, A., Evers, W. J. G., \& Tomic, W. (2001). Self-efficacy in eliciting social support and burnout among secondary-school teachers. Journal of Applied Social Psychology, 31(7), 1474-1491. https://doi.org/10.1111/j.1559-1816.2001.tb02683.x

Bulle, N. (2011). Comparing OECD educational models through the prism of PISA. Comparative Education, 47(4), 503-521. https://doi.org/10.1080/03050068.2011.555117

Canrinus, T. E., Helms-Lorenz, M., Beijaard, D., Buitink, J., \& Hofman, A. (2012). Self-efficacy, job satisfaction, motivation and commitment: Exploring the relationships between indicators of teachers' professional identity. European Journal of Psychology of Education, 27, 115-132. https://doi.org/10.1007/s10212-011-0069-2

Caprara, V. G., Barbaranelli, C., Borgogni, L., \& Petitta, L. (2003). Teachers', school staff's and parents' efficacy beliefs as determinants of attitudes toward school. European Journal of Psychology of Education, 18(1), 15-31. https://doi.org/10.1007/BF03173601

Collie, J. R., Shapka, D. J., \& Perry, E. N. (2012). School climate and social-emotional learning: predicting teacher stress, job satisfaction, and teaching efficacy. Journal of Educational Psychology, 104(4), 1189-1204. https://doi.org/10.1037/a0029356

Darling-Hammond, L., Chung, R., \& Frelow, F. (2002). Variation in teacher preparation: how well do different pathways prepare teachers to teach? Journal of Teacher Education, 53, 286. https://doi.org/10.1177/0022487102053004002

Enders, K. C., \& Bandalos, L. D. (2001). The relative performance of full information maximum likelihood estimation for missing data in structural equation models. Structural Equation Modeling, 8(3), 430-457. https://doi.org/10.1207/S15328007SEM0803_5

Federici, A. R. (2013). Principals' self-efficacy: relations with job autonomy, job satisfaction, and contextual constraints. European Journal of Psychology of Education, 28, 73-86. https://doi.org/10.1007/s10212-011-0102-5

Federici, A. R., \& Skaalvik, M. E. (2012). Principal self-efficacy: Relations with burnout, job satisfaction and motivation to quit. Social Psychology of Education, 15, 295-320. https://doi.org/10.1007/s11218-012-9183-5

Gennetian, L. A., Magnuson, K., \& Morris, P. A. (2008). From statistical associations to causation: What developmentalists can learn from instrumental variables techniques coupled with experimental data. Developmental Psychology, 44(2), 381-394. https://doi.org/10.1037/0012-1649.44.2.381

Giallo, R., \& Little, E. (2003). Classroom behaviour problems: The relationship between preparedness, classroom experiences, and self-efficacy in graduate and student teachers. Australian Journal of Educational \& Developmental Psychology, 3, 21-34.

Granziera, H., \& Perera, N. H. (2019). Relations among teachers' self-efficacy beliefs, engagement, and work satisfaction: A social cognitive view. Contemporary Educational Psychology, 58, 75-84. https://doi.org/10.1016/j.cedpsych.2019.02.003

Green, A., \& Muñoz, M. (2016). Predictors of new teacher satisfaction in urban schools: effects of personal characteristics, general job facets, and teacher-specific job facets. Journal of School Leadership, 26(1), 92-123. https://doi.org/10.1177/105268461602600104

Heck, R., \& Thomas, S. (2020). An introduction to multilevel modeling techniques: MLM and SEM approached. New York, NY, USA: Routledge.

Heise, D. (1975). Causal Analysis. New York, NY, USA: Wiley. 
Høigaard, R., Giske, R., \& Sundsli, K. (2012). Newly qualified teachers' work engagement and teacher efficacy influences on job satisfaction, burnout, and the intention to quit. European Journal of Teacher Education, 35(3), 347-357. https://doi.org/10.1080/02619768.2011.633993

Holmbeck, G. (1997). Toward terminological, conceptual, and statistical clarity in the study of mediators and moderators: examples from the child-clinical and pediatric psychology literatures. Journal of Consulting and Clinical Psychology, 65(4), 599610. https://doi.org/10.1037/0022-006X.65.4.599

Hu, L., \& Bentler, M. P. (1999). Cutoff criteria for fit indexes in covariance structure analysis: Conventional criteria versus new alternatives. Structural Equation Modeling: A Multidisciplinary Journal, 6(1), 1-55. https://doi.org/10.1080/10705519909540118

IBM Corp. (2015). IBM SPSS statistics for windows; version 23.0. Armonk, NY, USA: IBM Corp.

Jöreskog, K. G. (1971). Simultaneous factor analysis in several populations. Psychometrika, 36(4), 409-426. https://doi.org/10.1007/BF02291366

Katsantonis, G. I. (2020a). Investigation of the Impact of School Climate and Teachers' Self-Efficacy on Job Satisfaction: A CrossCultural Approach. European Journal of Investigation in Health, Psychology and Education, 10(1), 119-133. https://doi.org/10.3390/ejihpe10010011

Katsantonis, I. (2020b). Factors Associated with Psychological Well-Being and Stress: A Cross-Cultural Perspective on Psychological Well-Being and Gender Differences in a Population of Teachers. Pedagogical Research, 5(4), em0066. https://doi.org/10.29333/pr/8235

Katsantonis, G. I. (2020c). Teachers' self-efficacy, perceived administrative support and positive attitude toward students: Their effect on coping with job-related stress. Hellenic Journal of Psychology, 17(1), 1-14. https://doi.org/10.26262/hjp.v17i1.7843

Klassen, R., \& Chiu, M. M. (2010). Effects on teachers' self-efficacy and job satisfaction: teacher gender, years of experience, and job stress. Journal of Educational Psychology, 102(3), 741-756. https://doi.org/10.1037/a0019237

Kline, R. (2013). Reverse arrow dynamics: Feedback loops and formative measurement. In G. Hancock \& R. Mueller (Eds.) Structural Equation Modeling: A Second Course (pp. 41-80). Charlotte, NC, USA: Information Age Publishing, Inc.

Kline, R. (2016). Principles and practice of structural equation modeling (4th ed.). New York, NY, USA: The Guilford Press.

Knoblauch, D., \& Woolfolk Hoy, A. (2008). "Maybe I can teach those kids." The influence of contextual factors on student teachers' efficacy beliefs. Teaching and Teacher Education, 24, 166-179. https://doi.org/10.1016/j.tate.2007.05.005

Labone, E. (2004). Teacher efficacy: maturing the construct through research in alternative paradigms. Teaching and Teacher Education, 20, 341-359. https://doi.org/10.1016/j.tate.2004.02.013

Maartens, P. M., \& Haase, F. R. (2006). Advanced applications of structural equation modeling in counseling psychology research. The Counseling Psychologist, 34(6), 878-911. https://doi.org/10.1177/0011000005283395

Malinen, O., \& Savolainen, H. (2016). The effect of perceived school climate and teacher efficacy in behavior management on job satisfaction and burnout: A longitudinal study. Teaching and Teacher Education, 60, $144-152$. https://doi.org/10.1016/j.tate.2016.08.012

OECD. (2019). TALIS 2018 Technical Report. Paris, France: OECD Publishing.

Paxton, M. P., Hipp, R. J., \& Marquart-Pyatt, S. (2011). Nonrecursive models: Endogeneity, reciprocal relationships, and feedback loops. Thousand Oaks, CA, USA: Sage Publications

R Core Team. (2018). R: A language and environment for statistical computing. Vienna, Austria: R Foundation for Statistical Computing.

Rosseel, Y. (2012). Lavaan: An R package for structural equation modeling. Journal of Statistical Software, 48(2), 1-36. https://doi.org/10.18637/jss.v048.i02

Rots, I., \& Aelterman, A. (2009). Teacher education graduates' entrance into the teaching profession: Development and test of a model. European Journal of Psychology of Education, 24(4), 453-471. https://doi.org/10.1007/BF03178761

Sass, A. D., \& Schmitt, A. T. (2013). Testing measurement and structural invariance: implications for practice. In Teo, T. (Eds.) Handbook of Quantitative Methods for Educational Research (pp. 315-346). Rotterdam, the Netherlands: Sense Publishers.

Schaubroeck, J. (1988). Specifying nonrecursive models in organizational research. Academy of Management Proceedings, 1988(1), 378-382. https://doi.org/10.5465/ambpp.1988.4981236

Schaubroeck, J. (1990). Investigating reciprocal causation in organizational behavior research. Journal of Organizational Behavior, 11, 17-28. https://doi.org/10.1002/job.4030110105

Schwarzer, R., \& Hallum, S. (2008). Perceived teacher self-efficacy as a predictor of job stress and burnout: Mediation analyses. Applied Psychology: An International Review, 57, 152-171. https://doi.org/10.1111/j.1464-0597.2008.00359.x

Simbula, S., Guglielmi, D., \& Schaufeli, W. (2011). A three-wave study of job resources, self-efficacy, and work engagement among Italian schoolteachers. European Journal of Work and Organizational Psychology, 20 (3), 285-304. https://doi.org/10.1080/13594320903513916

Skaalvik, M. E., \& Skaalvik, S. (2014). Teacher self-efficacy and perceived autonomy: Relations with teacher engagement, job satisfaction, and emotional exhaustion. Psychological Reports: Employment Psychology \& Marketing, 114(1), 68-77. https://doi.org/10.2466/14.02.PR0.114k14w0 
Tschannen-Moran, M., \& Woolfolk Hoy, A. (2001). Teacher efficacy: capturing an elusive construct. Teaching and Teacher Education, 17(7), 783-805. https://doi.org/10.1016/S0742-051X(01)00036-1

Tschannen-Moran, M., \& Woolfolk Hoy, A. (2007). The differential antecedents of self-efficacy beliefs of novice and experienced teachers. Teaching and Teacher Education, 23, 944-956. https://doi.org/10.1016/j.tate.2006.05.003

Tschannen-Moran, M., Woolfolk Hoy, A., \& Hoy, W. (1998). Teacher efficacy: Its meaning and measure. Review of Educational Research, 68(2), 202-248. https://doi.org/10.3102/00346543068002202

Vieluf, S., Kunter, M., \& van de Vijver, J. R. F. (2013). Teacher self-efficacy in cross-national perspective. Teaching and Teacher Education, 35, 92-103. https://doi.org/10.1016/j.tate.2013.05.006

Wang, H., Hall, N., \& Rahimi, S. (2015). Self-efficacy and causal attributions in teachers: Effects on burnout, job satisfaction, illness, and quitting intentions. Teaching and Teacher Education, 47, 120-130. https://doi.org/10.1016/j.tate.2014.12.005

Williams, T., \& Williams, K. (2010). Self-efficacy and performance in mathematics: Reciprocal determinism in 33 nations. Journal of Educational Psychology, 102(2), 453-466. https://doi.org/10.1037/a0017271

Wong, C., \& Law, S. K. (1999) Testing reciprocal relations by nonrecursive structural equation models using cross-sectional data. Organizational Research Methods, 2(1), 69-87. https://doi.org/10.1177/109442819921005

Wooldridge, J. (2013). Introductory econometrics: A modern approach. Mason, $\mathrm{OH}, \mathrm{USA}$ : Cengage Learning

Xanthopoulou, D., Bakker, A., Demerouti, E., \& Schaufeli, W. (2007). The role of personal resources in the job demands-resources model. International Journal of Stress Management, 14(2), 121-141. https://doi.org/10.1037/1072-5245.14.2.121

Yuan, K.-H., \& Bentler, P. M. (2000). Three likelihood-based methods for mean and covariance structure analysis with nonnormal missing data. Sociological Methodology, 30, 165-200. https://doi.org/10.1111/0081-1750.00078

Zakariya, Y. F. (2020). Effects of school climate and teacher self-efficacy on job satisfaction of mostly STEM teachers: a structural multigroup invariance approach. International Journal of STEM Education, 7. https://doi.org/10.1186/s40594-020-00209-4

Zee, M., \& Koomen, M. Y. H. (2016). Teacher Self-efficacy and its effects on classroom processes, student academic adjustment, and teacher well-being: A synthesis of 40 years of research. Review of Educational Research, 86(4), 1-35. https://doi.org/10.3102/0034654315626801 